\title{
Application of FTIR and Raman spectroscopy to characterisation of bioactive materials and living cells
}

\author{
I. Notingher ${ }^{\mathrm{a}, *}$, J.R. Jones ${ }^{\mathrm{a}}$, S. Verrier ${ }^{\mathrm{a}, \mathrm{b}}$, I. Bisson $^{\mathrm{b}}$, P. Embanga ${ }^{\mathrm{a}}$, P. Edwards ${ }^{\mathrm{b}}$, J.M. Polak ${ }^{\mathrm{b}}$ \\ and L.L. Hench ${ }^{\mathrm{a}}$ \\ ${ }^{a}$ Department of Materials, Imperial College of Science, Technology and Medicine, \\ South Kensington Campus, London SW7 2BP, UK \\ ${ }^{\mathrm{b}}$ Tissue Engineering Centre, Imperial College of Science, Technology and Medicine, \\ Chelsea and Westminster Campus, London SW10 9NH, UK
}

\begin{abstract}
Both Fourier Transform Infrared (FTIR) and Raman spectroscopy have been applied to the in vitro characterisation of biomaterials, mainly surface reactions leading to the formation of a biologically active hydroxycarbonate apatite (HCA) layer on the sample surface when immersed in simulated body fluids (SBF). The HCA layer indicates the degree of bioactivity of the sample, because it leads to a strong bond between the biomaterial and living tissue. Reflection measurements using FTIR allow quick, non-destructive detection of the HCA layer for solid and powder samples. Due to the low Raman scattering efficiency and low absorption of water in the visible-near infrared region, Raman micro-spectroscopy was successfully used for the in situ characterisation of 20 and $40 \mu \mathrm{m}$ diameter 45S5 Bioglass ${ }^{\circledR}$ fibres. The in situ capabilities of the Raman micro-spectrometer have also been extended to the characterisation of living cells attached on bioinert silica and bioactive 45S5 Bioglass ${ }^{\circledR}$ and 58S substrates. Using a high power $785 \mathrm{~nm}$ laser, living cells in physiological conditions can be real-time sampled over long periods of time without inducing cell damage and with good signal strength. Cell death can be monitored because it proved to induce strong changes in the Raman signature in the spectral regions $1000-1150 \mathrm{~cm}^{-1}$ and $1550-1650 \mathrm{~cm}^{-1}$.
\end{abstract}

\section{Introduction}

Tissue engineering is a concept, based on the idea of making long-term repair and replacement systems for failing human tissues and organs, that can be supplied on demand for therapeutic applications from skin grafts to organ replacements. One approach consists of growing cells on a scaffold with the required properties. The materials provide a scaffold to support cell growth in 3 dimensions, but also to enhance and stimulate cell differentiation to obtain specific constructs that mimic the complex structures and physiological behaviour of natural tissues.

\subsection{Need for bioactive materials}

In early bone tissue replacements, materials used for the implanted prosthesis were bioinert, such as metals, alumina, zirconia, polyethylene, etc. with an average lifetime of 15 years [1-3]. The need for bone replacement due to the decrease of bone strength at about the age of 50, combined with the increase of the human life expectancy to about 80 years, makes the lifetime of traditional bioinert prostheses

\footnotetext{
*Corresponding author. Tel.: +44 20759 46813; Fax: +44 20759 46809; E-mail: notingher@ic.ac.uk.
} 
too short. Therefore, many patients require more surgical interventions. One reason for failure of the prostheses made of bioinert materials is that there is no biological bond between the prosthesis and host tissue, which in time leads to wearing and deterioration of the implant $[1,4,5]$. A second reason is the weakening of healthy bone due to mechanical loading of the implant because of the mismatch between the mechanical properties of the bone and implant $[1,5,6]$.

The aim in developing bioactive materials for new prostheses is to match the mechanical properties and to stimulate a biochemical response from the tissue which will lead to the formation of a strong bond ("biological fixation") between the prosthesis and the tissue. Moreover, the bioactive material must facilitate the augmentation and regeneration of tissue instead of mere replacement. Of bioactive materials developed up to now, bioactive glasses based on $\mathrm{SiO}_{2}, \mathrm{Na}_{2} \mathrm{O}, \mathrm{CaO}$ and $\mathrm{P}_{2} \mathrm{O}_{5}$ have the closest mechanical properties to cortical bone and elicit a quick biochemical response when placed in physiological fluids [15,7]. This biochemical response consists of ion exchange at the glass surface leading to the formation of a biological hydroxycabonate apatite (HCA) layer on which bone cells attach and proliferate. The collagen produced by the bone cells bind to the HCA layer leading to bone regeneration $[1,7]$.

\subsection{Mechanism of bioactivity; factors affecting bioactivity}

The mechanism and the time scale involved in the formation of the HCA layer, stages $1-5$, and the growth of new bone, stages 6-11, on the bioactive glass implant are illustrated in Fig. 1 [1,7-11].

The degree of bioactivity of a material is determined by the rate of formation of HCA layer formation at its surface. The time required for the formation of the HCA layer depends on factors such as glass composition, glass structure and glass geometry [3,7,12]. Previous studies have shown that the increase of $\mathrm{SiO}_{2}$ concentration of the melt-derived glass slows down the formation of the HCA layer by reducing the availability of $\mathrm{Ca}^{2+}$ and $\mathrm{HPO}_{4}^{-}$to the solution $[3,13]$. At the same time the crystallisation of the glass reduces the bioactivity because the crystalline phase inhibits ion exchange [14]. Glass geometry is a critical factor because the geometry of an implant determines the surface area to solution volume ratio (SA/V) which controls the ion exchange rate $[3,10,15]$.

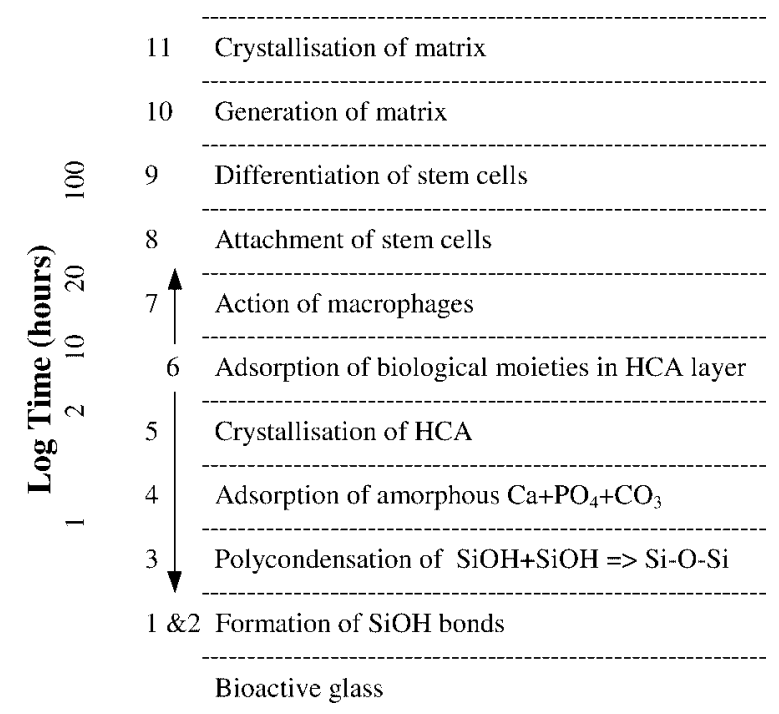

Fig. 1. Sequence of interfacial reactions involved in forming a bond between tissue and bioactive glasses [1,7-11]. 
The first reported bioactive glass was the melt-derived 45S5 Bioglass ${ }^{\circledR}\left(46.1 \mathrm{SiO}_{2}, 24.4 \mathrm{Na}_{2} \mathrm{O}, 26.9\right.$ $\mathrm{CaO}, 2.6 \mathrm{P}_{2} \mathrm{O}_{5} \mathrm{~mol} \%$ ) [7]. Since then, the 45S5 Bioglass ${ }^{\circledR}$ has been thoroughly characterised and new glasses with different composition and properties have been developed. The main development in the processing of new bioactive glasses is the sol-gel technique.

\subsection{Sol-gel and melt-derived glasses}

The sol-gel method allows a better control of bioactive properties by closely controlling the composition and microstructure of the material. Details of sol-gel processing of bioactive materials can be found in [16-19]. The glasses obtained by this technique have a nanometer-scale porosity that can be controlled to change the dissolution rate. This porosity also ensures a higher bioactivity due to a higher SA/V ratio (more than 50 times) than the melt-derived glass. Trabecular bone can be mimicked by foaming the glass to provide $10-200 \mu \mathrm{m}$ interconnected pores [20]. The lower sol-gel processing temperature $\left(600-700^{\circ} \mathrm{C}\right)$ permits a higher control of glass purity. The sol-gel technique also allows much higher concentration of $\mathrm{SiO}_{2}$ to be used (up to $90 \mathrm{~mol} \%$ ) without loss of bioactivity. The main sol-gel bioactive glass composition is the $58 \mathrm{~S}$ glass $\left(60 \mathrm{SiO}_{2}, 36 \mathrm{CaO}, 4 \mathrm{P}_{2} \mathrm{O}_{5} \mathrm{~mol} \%\right)$.

\subsection{Biomaterials characterisation}

In vitro studies are used to understand the factors that determine the properties of bioactive glass implants. The most common techniques used to characterise the surface reactions of bioactive samples immersed in simulated body fluids as a function of time are X-ray diffraction (XRD), inductively coupled plasma (ICP), optical microscopy (OM), scanning electron microscopy (SEM) and vibrational spectroscopy [5].

XRD is one of the most common techniques used in the characterisation of materials structure. However, its application to the characterisation of bioactivity is limited due to the low signal strength of thin coatings of HCA [5]. ICP provides useful information regarding the dissolution kinetics by analyses of the ion composition of the solution. Using this technique, the concentration increase of silicon, sodium and calcium and the decrease of phosphorus in simulated body fluids have been seen [21]. OM and SEM are the most common techniques for surface visualisation of the bioactive glass surfaces. Photographs of high spatial resolution can be acquired.

Vibrational spectroscopy is one of the most common techniques used to study the chemical composition and surface properties of solid samples. Its main advantages are reduced cost, rapid, quantitative results, non-destructive non-contact sampling of either large or small areas and possibilities for in situ measurements. The two main techniques, Fourier Transform Infrared (FTIR) and Raman spectroscopy, allow complementary results to be obtained, depending on the information required. FTIR is most common, being used non-destructively to measure reflection spectra of reacted samples. Raman spectroscopy has also been used for the characterisation of bioactive samples and its big advantage comes from the low Raman signal and low absorption of water in visible and near-infrared region. Thus, in situ characterisation of biomaterials surface reactions is possible using Raman spectroscopy. Moreover, the combination of Raman spectroscopy with optical microscopy makes possible in situ measurements with high spatial resolution.

\subsection{Need for in situ spectroscopy to monitor cells in vitro and in vivo}

As described above, the characterisation of the bioactive properties of biomaterials is important to understand the interaction between implants and host tissues. However, the study of how biomaterials 
change host tissues is equally important. It has been shown that 45S5 Bioglass ${ }^{\circledR}$ has an active role in cell adhesion and proliferation related to gene activation caused by cell-substrate interactions (e.g., controlled ion release) $[22,23]$. The in situ real-time analysis of living cells in physiological conditions would allow the study of the interaction of the cells with different biomaterials, the effects of various chemicals and stimuli, etc.

FTIR microscopy has already been applied to the analysis of cell death and cell cycle [24-28] but these studies cannot be carried out in situ due to the strong absorption of water in the infrared region. Raman micro-spectroscopy overcomes this obstacle, Puppels et al. reported the first Raman spectra of living cells in 1990 [29]. However, the main problems in Raman study of biological samples are the low signal strength and the damage induced by the lasers used for excitation. UV and visible lasers are not of much use in analysing living cells because of the damage induced to the cells at low power levels and short irradiation times [30,31].

The objective in tissue engineering is to sample individual cells in culture for hours or days, in order to monitor spectral changes that can be correlated with changes in the cell phenotype and cell growth within engineered tissue constructs. For this, the cells have to be kept in normal physiological conditions (temperature, $\mathrm{CO}_{2}$, medium change and nutrients supply) and the Raman spectra must be remotely recorded at a wavelength where high powers and long irradiation times can be used. The objective is to record high quality spectra over long periods of time without damaging the cells.

The development of new near-infrared lasers and high sensitivity CCD detectors allow high powers to be used to obtain reasonable Raman spectra from living cells in short times without inducing cell death. Also, the near-infrared lasers can be used for long time irradiation exposure to follow biological events in individual cells [31].

In this paper, the authors review the application of FTIR and Raman spectroscopy to the characterisation of both bioactive glasses and living cells in physiologic conditions. We present the capabilities of FTIR and Raman techniques in detecting the HCA layer formation on the surface of 45S5 Bioglass ${ }^{\circledR}$ and $58 \mathrm{~S}$ substrates, powders and fibres. The recent results using the Raman micro-spectrometer in studying living cells are also reviewed, emphasising the potential of this technique in tissue engineering.

\section{Bioactive materials characterisation: substrates, powders, fibres, foams}

\subsection{Fourier transform infrared spectroscopy (FTIR)}

FTIR has been intensively used in the study of the surface reaction of bioactive materials after immersion in simulated body fluid (SBF) solution [13,32-34] and after implantation [35]. Both diffuse reflectance and specular reflectance can be used for monitoring the formation of the HCA layer at the surface of bioactive materials. The HCA layer is characterised by the $\mathrm{P}-\mathrm{O}$ bending vibration peaks at 560 and $604 \mathrm{~cm}^{-1}$ and the $\mathrm{P}-\mathrm{O}$ asymmetric stretching vibration bands between 1000 and $1150 \mathrm{~cm}^{-1}$ [13, 36]. The peaks corresponding to the bending vibration are most used to discriminate between HCA and bioactive material since the $\mathrm{P}-\mathrm{O}$ stretching band is superimposed on the $\mathrm{Si}-\mathrm{O}$ stretching band corresponding to bioactive glasses while the absorption band corresponding to $\mathrm{Si}-\mathrm{O}$ bending is between 400 and $500 \mathrm{~cm}^{-1}$ [13], at lower frequencies compared with $\mathrm{P}-\mathrm{O}$ bending in HCA.

Figure 2 shows the reflectance spectra of $58 \mathrm{~S}$ bioactive foam as function of immersion time in SBF: 1 hour, 8 hours and 3 days. 


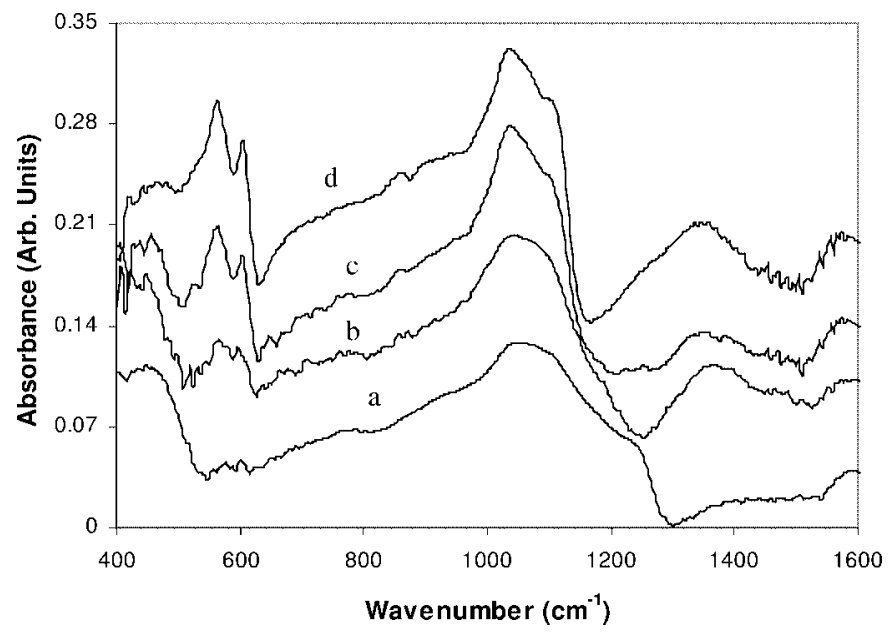

Fig. 2. Reflectance spectra of $58 \mathrm{~S}$ foam after immersion in SBF at $37^{\circ} \mathrm{C}$ : a - reference, $\mathrm{b}-1$ hour, $\mathrm{c}-8$ hours, $\mathrm{d}-3$ days.

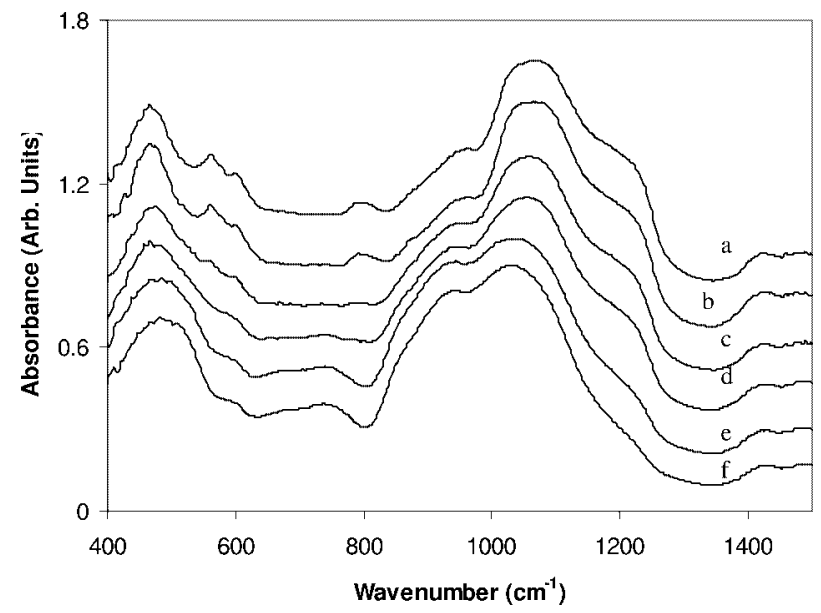

Fig. 3. FTIR spectra of $45 \mathrm{~S} 5$ powders immersed in SBF at various concentrations for 22 hours: (a) $0.0002 \mathrm{~g} \mathrm{ml}^{-1}$, (b) $0.0015 \mathrm{~g} \mathrm{ml}^{-1}$, (c) $0.002 \mathrm{~g} \mathrm{ml}^{-1}$, (d) $0.005 \mathrm{~g} \mathrm{ml}^{-1}$, (e) $0.01 \mathrm{~g} \mathrm{ml}^{-1}$, (f) $0.015 \mathrm{~g} \mathrm{ml}^{-1}$.

The magnitude of HCA peaks at 560 and $605 \mathrm{~cm}^{-1}$ increases relative to the foam $\mathrm{Si}-\mathrm{O}$ peaks at $450 \mathrm{~cm}^{-1}$ as the immersion time is longer. This indicates that the HCA layer is thicker for the samples soaked in SBF solution for longer times.

However, the signal-to-noise ratio of the reflection spectra is poor due to the porous surface, 600 interferograms being needed to obtain the spectra in Fig. 2. Therefore, the easiest application of FTIR is the study of bioactive powders with a $\mathrm{KBr}$ diffuse reflectance device. In this case, the signal is much stronger and the preparation time is less. Figures 3 and 4 show the spectra of $45 \mathrm{~S} 5$ and $58 \mathrm{~S}$ powders immersed in SBF solution for 22 hours at different concentrations: 0.0002, 0.0015, 0.002, 0.005, 0.01 and $0.015 \mathrm{~g} \mathrm{ml}^{-1}$.

In Fig. 3, the characteristic twin peaks at 571 and $604 \mathrm{~cm}^{-1}$, indicating HCA formation, were present at glass concentrations between 0.001 and $0.002 \mathrm{~g} \mathrm{ml}^{-1}$. However, the intensity of the twin peaks decreased as glass concentration increased. At glass concentrations of 0.005 to $0.015 \mathrm{~g} \mathrm{ml}^{-1}$, the twin $\mathrm{P}-\mathrm{O}$ 


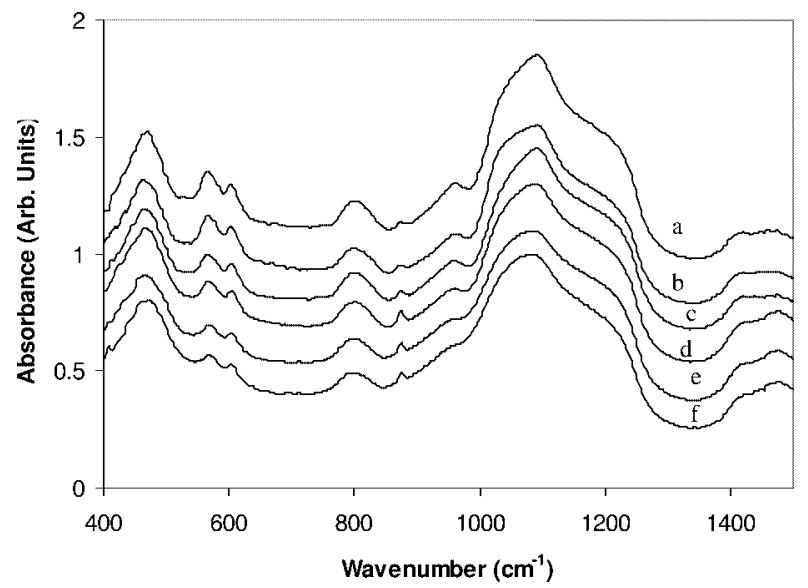

Fig. 4. FTIR spectra of $58 \mathrm{~S}$ powders immersed in SBF at various concentrations for 22 hours: (a) $0.0002 \mathrm{~g} \mathrm{ml}^{-1}$, (b) $0.0015 \mathrm{~g} \mathrm{ml}^{-1}$, (c) $0.002 \mathrm{~g} \mathrm{ml}^{-1}$, (d) $0.005 \mathrm{~g} \mathrm{ml}^{-1}$, (e) $0.01 \mathrm{~g} \mathrm{ml}^{-1}$, (f) $0.015 \mathrm{~g} \mathrm{ml}^{-1}$.

bend peaks were not present; instead a single peak corresponding to amorphous calcium phosphate was observed and the $\mathrm{P}-\mathrm{O}$ stretch peak was not present. Instead, the spectra exhibited $\mathrm{Si}-\mathrm{O}-\mathrm{Si}$ stretch and $\mathrm{Si}-\mathrm{O}-\mathrm{Si}$ bend bands at 1030 and $470 \mathrm{~cm}^{-1}$ respectively.

A small amorphous P-O peak was present at approximately $600 \mathrm{~cm}^{-1}$ [20], implying that HCA formation was inhibited at high glass concentrations. The amorphous peak could represent the presence of precursors to hydroxyapatite, either octocalcium phosphate (OCP) or amorphous calcium phosphate (ACP) [37]. This was confirmed by XRD analysis (not shown). In fact, XRD analysis showed that calcite (calcium carbonate) was deposited on the surface of 45S5 powders at a glass concentration of $0.015 \mathrm{~g} \mathrm{ml}^{-1}$, implying that calcite may have deposited on the glass surface at the expense of the HCA layer [20].

The data indicates that the ratio of calcium to phosphorous ions in solution increased as the glass concentration increased, from approximately $6 \mathrm{Ca} / \mathrm{P}$ (at a glass concentration of $0.001 \mathrm{~g} \mathrm{ml}^{-1}$ ) to $130 \mathrm{Ca} / \mathrm{P}$ (at a glass concentration of $0.015 \mathrm{~g} \mathrm{ml}^{-1}$ ) [20]. The phosphorous and calcium ions migrate from the solution to the surface of the glass to nucleate HCA precursors. Therefore at high concentrations, when there are excessive calcium ions in solution, causing an increase in $\mathrm{pH}$ of the solution, calcium carbonate forms at the expense of HCA.

In Fig. 4, the peaks at 570 and $600 \mathrm{~cm}^{-1}$ corresponding to crystalline HCA formation were present at all glass concentrations. However intensity of the $\mathrm{P}-\mathrm{O}$ bending peaks became less sharp as glass concentration increased. A carbonate peak at $875 \mathrm{~cm}^{-1}$ developed at $0.005 \mathrm{~g} \mathrm{ml}^{-1}$ and increased in intensity as glass concentration was increased. This could demonstrate carbonate being incorporated into the apatite layer to form $\mathrm{HCA}$ or calcium carbonate deposition in 58S gel-glass at high glass concentrations at the expense of the HCA layer, as it was on $45 \mathrm{~S} 5$ reacted at a concentration of $0.010 \mathrm{~g} \mathrm{ml}^{-1}$.

Comparison of Figs 3 and 4 shows that the rate of HCA formation on gel-derived bioactive glasses was higher than on the melt-derived glasses, and that the concentration dependence was more pronounced on the $45 \mathrm{~S} 5$ powders. This is due to the gel-glasses exhibiting a much higher specific surface area than dense melt-derived glasses due to the mesoporous structure inherent in the sol-gel process. The high surface area enhances glass dissolution and the mesopores act as nucleation sites for HCA layer formation. 


\subsection{Raman micro-spectroscopy}

Although FTIR can be successfully used for the in vitro characterisation of biomaterials, in situ measurements are hindered by the strong absorption of water in the infrared region. Raman spectroscopy overcomes these problems, allowing in situ studies of the same sample over long periods of times. The adaptation of the optical microscope to Raman spectrometers also results in high spatial resolution. In order to emphasise both advantages of Raman micro-spectroscopy, this section presents in situ results obtained from $20 \mu \mathrm{m}$ and $40 \mu \mathrm{m}$ diameter 45S5 melt-derived optical fibres supplied by Mo-Sci Corporation, Rolla, Missouri, USA. The Mo-Sci $20 \mu \mathrm{m}$ were also coated with an organic layer of A-174 Silquest silane (gamma-methacryloxypropyltrimethoxysilane, $\mathrm{CH}-\mathrm{C}\left(\mathrm{CH}_{3}\right) \mathrm{CO}_{2} \mathrm{CH}_{2} \mathrm{CH}_{2} \mathrm{CH}_{2} \mathrm{Si}\left(\mathrm{OCH}_{3}\right)_{3}$, manufactured by Witco Corporation).

Optical fibres have been used for coupling the Raman spectrometer to the sample for some time. There are, however, optical fibre compositions that are also bioactive, and few studies have been carried out to investigate the possible use of fibre optics simultaneously as a light conducting medium and biomedical implant. Such a combination may offer advantages in terms of portability, flexibility of sampling and provide in situ information of biological transformations taking place. One application of such combination would be the remote interrogation of cells supported on bioactive optical fibre scaffolds while subjected to toxic agents.

Mo-Sci fibres were immersed in $20 \mathrm{ml}$ of simulated body fluid (SBF) $(0.0266 \mathrm{~g}$ for the $20 \mu \mathrm{m}$ and $0.0532 \mathrm{~g}$ for the $40 \mu \mathrm{m}$ fibres to obtain a sample surface area to solution volume ratio $S A / V=1.0$ ). The flasks were placed in an orbital shaker under $175 \mathrm{rpm}$ at $37^{\circ} \mathrm{C}$. Randomly selected fibres on which spectra were going to be taken were suspended $10 \mathrm{~mm}$ above the base of the flask to avoid signal interference. For the collection of spectra a Renishaw 2000 spectrometer was used, equipped with a wavelength-stabilized $785 \mathrm{~nm}$ diode laser.

Since previous results (SEM and Raman spectroscopy) of the dissolution tests of the fibres have shown that the initial stage of HCA formation on the surface of the fibres is heterogeneous, the beam spot size was increased to $10 \mu \mathrm{m} \times 10 \mu \mathrm{m}$ for the Raman spectra measurement. Furthermore, for each sample 6 spectra were taken by automatically moving the beam spot to cover a $20 \mu \mathrm{m} \times 30 \mu \mathrm{m}$ area of the fibre. All spectra were taken using 20 seconds integration time, over a period 10-15 minutes and then averaged.

The Raman spectra of the 45S5 $20 \mu \mathrm{m}$ fibres after 5 hours, 1 day, 2 days and 4 days reaction in SBF are shown in Fig. 5.

The spectrum of the 45S5 unreacted fibre is dominated by the $\mathrm{P}-\mathrm{O}$ symmetric stretching peak at $946 \mathrm{~cm}^{-1}$. In HCA, the position of the P-O stretching appears shifted towards higher wavenumbers and is centred at $960 \mathrm{~cm}^{-1}$. Even though in the first 2 days little changes are seen in the Raman spectra, the spectrum corresponding to fibres after 4 days immersion in SBF indicated a high degree of reactivity. Apart from the main peak at $960 \mathrm{~cm}^{-1}$, the $\mathrm{P}-\mathrm{O}$ asymmetric stretching at $1077 \mathrm{~cm}^{-1}$ is also present in the reacted spectrum $[38,39]$.

The Raman spectra of $40 \mu \mathrm{m}$ 45S5 fibres after 5 hours, 1 day, 2 days and 4 days reaction in SBF are shown in Fig. 6. The Raman spectra indicate that the reactions leading to HCA layer formation occur faster, with significant changes even after 2 days. Even after 1 day, the $\mathrm{P}-\mathrm{O}$ symmetric stretching peak broadens and shifts slightly toward higher wavenumbers, after 2 days the HCA peak at $960 \mathrm{~cm}^{-1}$ becoming well resolved.

An analysis of the fibre surface topography obtained from AFM (not shown) revealed that the fibre surface was not homogeneous. On average Mo-Sci $20 \mu \mathrm{m}$ fibres were smoother that Mo-Sci $40 \mu \mathrm{m}$ 


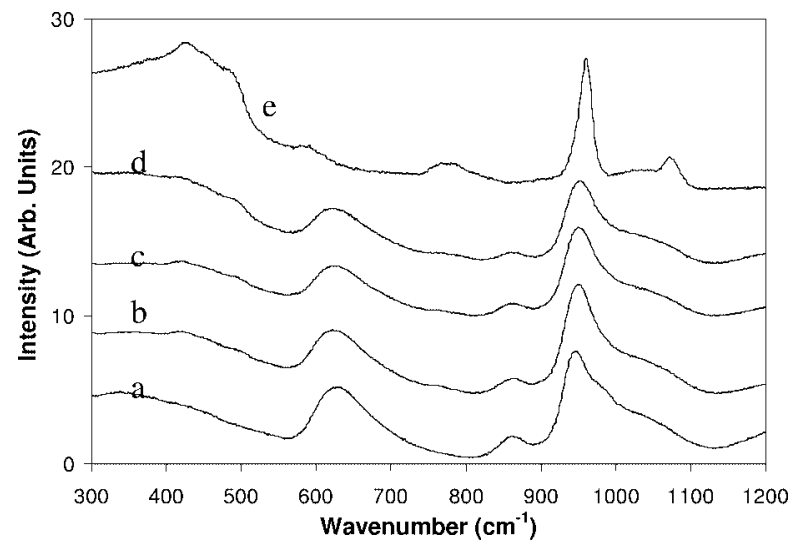

Fig. 5. In situ Raman spectra of $20 \mu \mathrm{m}$ diameter $45 \mathrm{~S} 5 \mathrm{Mo}$-Sci fibres after immersion in $\mathrm{SBF}$ at $37^{\circ} \mathrm{C}$ : $\mathrm{a}-$ reference, $\mathrm{b}-5$ hours, $\mathrm{c}-1$ day, $\mathrm{d}-2$ days, $\mathrm{e}-4$ days.

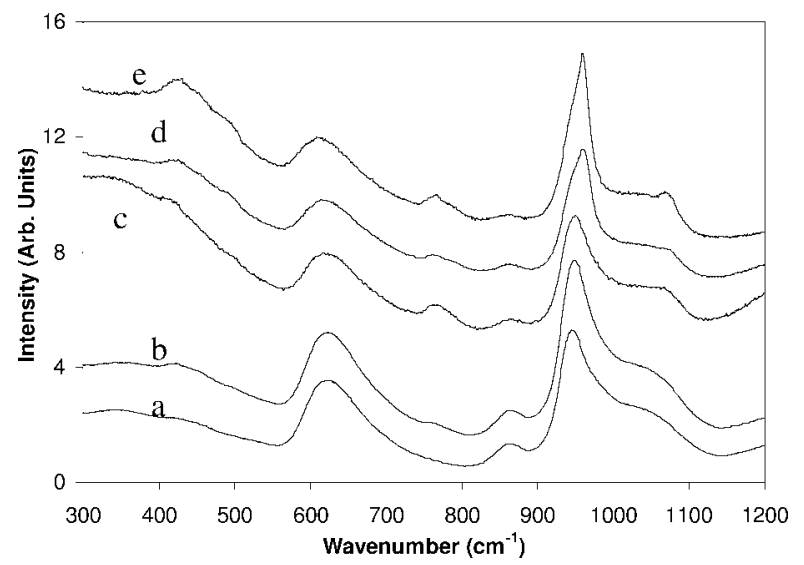

Fig. 6. In situ Raman spectra of $40 \mu \mathrm{m} 45 \mathrm{~S} 5 \mathrm{Mo}-\mathrm{Sci}$ fibres after immersion in SBF at $37^{\circ} \mathrm{C}$ : a - reference, $\mathrm{b}-5$ hours, $\mathrm{c}-$ 1 day, $\mathrm{d}-2$ days, $\mathrm{e}-4$ days.

fibres. This was probably due to the silane coating on Mo-Sci $20 \mu \mathrm{m}$. Furthermore, Mo-Sci $40 \mu \mathrm{m}$ produced higher $\mathrm{P}-\mathrm{O}$ peaks that Mo-Sci $20 \mu \mathrm{m}$, especially between 1 and 4 days. This is due to the fact that initially the silane coating slows down the ion exchange (Stages 1-2 in Fig. 1). As the dissolution proceeds the coating disintegrates and allows the ions to migrate freely. Whereas, the ion exchange between the fibre and SBF solution is not hindered and proceeds more freely it slows down toward day 4 as the ion concentration between the Mo-Sci $40 \mu \mathrm{m}$ and the solution reaches equilibrium. Peltola et al. reported specifically on the relationship between topography and bioactivity of bioactive fibres [40]. They reported that the surface structure before immersion in SBF on the nanometer scale is one of the most important factors controlling the in vitro bioactivity of silica fibres.

\section{Raman spectroscopy of living cells}

Although vibrational spectroscopy has been used for the characterisation of biomaterials for long time, few results have been published regarding the use of FTIR and Raman spectroscopy in the study of 
living cells used in tissue engineering. FTIR microscopy, connected to synchrotron infrared sources, was successfully used in the study of cell cycle and cell death [26]. However, the strong interference from water made in situ measurements impossible. Raman micro-spectroscopy has more capabilities due to the low Raman scattering efficiency and low absorption of water in the near-infrared. Therefore, visible and near-infrared lasers can be used to probe individual living cells in their physiological environment. Also, the spatial resolution is better in the visible and near-infrared range allowing independent measurements of the nucleus and cytoplasm of a single cell. The objective is to sample individual cells in culture for hours or days in order to monitor spectral changes that can be correlated with changes in the cell phenotype and cell growth within engineered tissue constructs.

\subsection{Effect of laser irradiation on cell lifetime}

Due to the low Raman scattering efficiency of biological samples, lasers with high powers have to be used to obtain strong signal strength. These lasers can damage the cells, especially if irradiations of long duration are required. Lasers operated in the UV region offer stronger signals but they are harmful because of the strong absorption of nucleic acids and proteins in this region, which leads to their denaturation [41,42]. In the visible region nucleic acids and proteins have less absorption, but cell damage occurs even at very low laser powers and short irradiations. It was reported that at $488 \mathrm{~nm}$ and $514 \mathrm{~nm}$ wavelengths, $5 \mathrm{~mW}$ irradiation for 5 minutes led to degradation of living human lymphocytes [43]. The authors suggested that the cell damage occurred due to photochemical reactions initiated by the laser in the cytoplasm, since no damage was observed when separated DNA molecules were irradiated [30]. We have recently shown that cell damage occurred when mouse lung epithelial (MLE-12 line) cells were irradiated by the same wavelength visible lasers. Typical cell damage is shown in Fig. 7, which presents micrographs of MLE-12 cells before and after 10 minutes laser irradiation at $488 \mathrm{~nm}, 5 \mathrm{~mW}$ [31].

Longer wavelength lasers at $660 \mathrm{~nm}$ were also tried [43], with positive results. At $660 \mathrm{~nm}$, cells survived 5 minutes irradiations of $20 \mathrm{~mW}$ laser power [43]. It was suggested that at longer wavelengths $(1064 \mathrm{~nm})$, lasers with powers even higher could be used but the Raman scattering efficiency decreases strongly as the wavelength is increased [44] which greatly decreases Raman signal strength. Thus we concluded that wavelengths around $800 \mathrm{~cm}^{-1}$ would be ideal for reducing cell damage while the Raman signal strength is reasonable [31].

Recently we showed that $785 \mathrm{~nm}$ is suitable for in situ Raman measurements, cells withstanding $115 \mathrm{~mW}$ laser powers over 40 minutes irradiation without change of morphology or Raman spec-

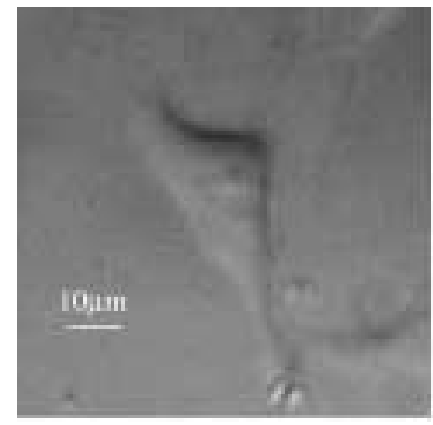

(a)

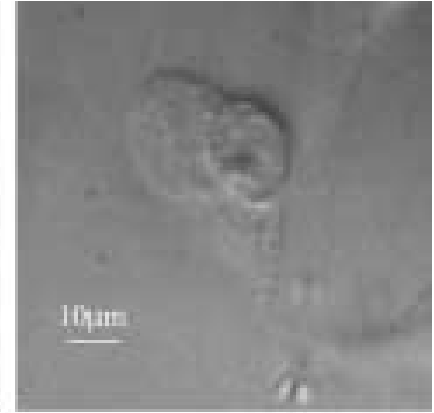

(b)

Fig. 7. The effect of laser irradiation at $488 \mathrm{~nm}$ on MLE-12 cells: (a) initial, (b) after 10 minutes irradiation at $5 \mathrm{~mW}$ laser power. 


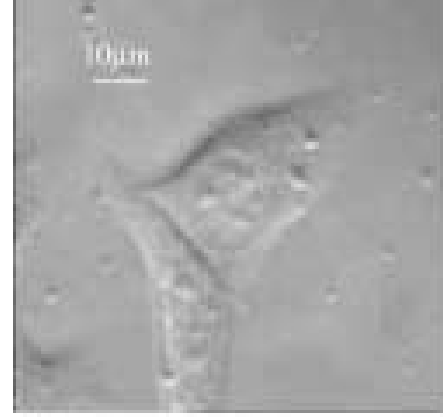

la!

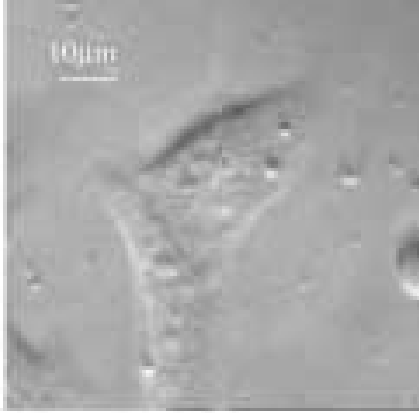

(b)

Fig. 8. Micrographs of MLE-12 cells before (a) and after 40 minutes irradiation at $115 \mathrm{~mW} 785 \mathrm{~nm}$ (b).

trum [31]. The lack of cell damage at this excitation wavelength at long irradiation time was tested by Trypan blue and morphological observation [31]. The Trypan blue tests indicated that cells are alive. Micrographs of MLE- 12 cells before and after 40 minutes laser irradiation at $785 \mathrm{~nm}$ and $115 \mathrm{~mW}$ power are presented in Fig. 8. There are no morphological changes apparent after 40 minutes exposure.

\subsection{Effects due to substrate: poly-L-lysine coated silica, 45 S5 Bioglass ${ }^{\circledR}$, 58 S glass}

Due to the small Raman signal from the cells, in order to ensure good quality spectra, a good confocal set-up of the Raman micro-spectrometer is required. This reduces the contribution of the substrate to the measured signal, which can be subtracted afterwards. Poly-L-lysine coated fused silica substrates are biologically inert, with a low Raman signal. Thus they were used as substrates for cell growth to measure the Raman spectra of living cells.

In the case of bioactive 45S5 Bioglass ${ }^{\circledR}$ and $58 \mathrm{~S}$ glass substrates, the substrate contribution to Raman signals is stronger, therefore a smaller aperture has to be used in front of the detector, which leads to longer measurement times in order to ensure the same spectrum quality (180 seconds compared to 80 120 seconds for silica). The Raman spectra of individual living MLE-12 cells cultured on poly-L-lysine coated silica, 45S5 Bioglass ${ }^{\circledR}$ and 58S glass are shown in Fig. 9.

Table 1 summarises the spectral peak assignments shown in Fig. 9 [31]. The spectra are dominated by the vibration of the nucleic acids and proteins, as shown in Fig. 9. The amide I peak at $1659 \mathrm{~cm}^{-1}$ and the $\mathrm{C}-\mathrm{C}$ skeletal vibrations at $937 \mathrm{~cm}^{-1}$ suggest that the predominant conformation of the proteins in the MLE-12 cells is $\alpha$-helical [45]. The DNA bands at $1095 \mathrm{~cm}^{-1}$ and $833 \mathrm{~cm}^{-1}$ indicate that the DNA is in the B form [46]. However, spectra (b) and (c) have some distortions due to the bioactive substrates. The spectrum of MLE-12 cells cultured on 45S5 Bioglass ${ }^{\circledR}$ shows an extra peak centred at $960 \mathrm{~cm}^{-1}$, which is difficult to be corrected. It is due to the $\mathrm{P}-\mathrm{O}$ symmetrical stretching in the HCA layer which is formed on the substrate surface [50].

However, this peak does not interfere with any important peak belonging to the DNA. Stronger interference from the substrate is noticed in the case of $58 \mathrm{~S}$ gel-glass, on which surface a layer of calcite is forming. The $\mathrm{CO}_{3}$ symmetric stretching at $1088 \mathrm{~cm}^{-1}$ interferes with the $1094 \mathrm{~cm}^{-1}$ DNA backbone peak, which could lead to erroneous interpretation [51]. 


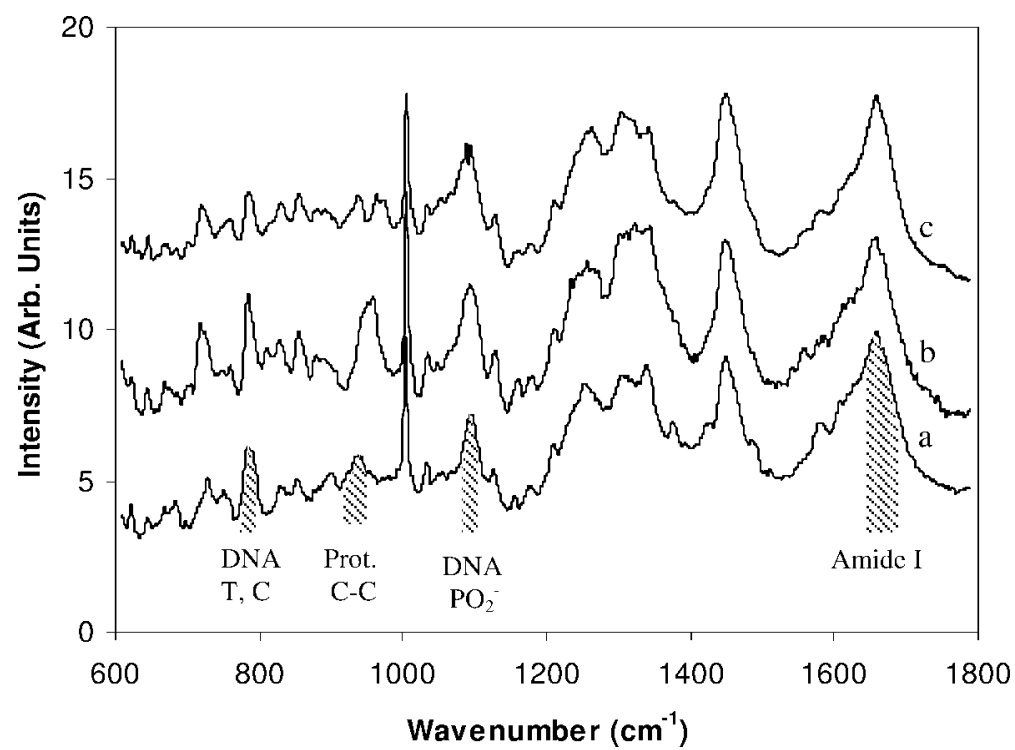

Fig. 9. Raman spectra individual living MLE-12 cells cultured on: (a) poly-L-lysine coated silica, (b) 45S5 Bioglass ${ }^{\circledR}$, (c) $58 \mathrm{~S}$ glass.

\subsection{Identification of dead cells}

The in situ identification of any changes in cell phenotype is very important in tissue engineering. We showed that specific changes occur in the spectra of dead cells which can be used to identify cell death before the cells detach from the substrate [31].

To obtain dead cells, cultured cells were deliberately left in the incubator for 4 days without changing the culture medium. This condition led to a high proportion of dead cells, as confirmed by Trypan blue tests. A typical spectrum of a dead cell is shown in Fig. 10b [31]. To better identify the spectral differences compared to a living cell, the difference spectrum was calculated (Fig. 10c).

The most important changes appear at 1578 and $1607 \mathrm{~cm}^{-1}$, the magnitudes of these peaks being higher for the dead cells. Cell death is also indicated by the presence of a peak at $1114 \mathrm{~cm}^{-1}$, which does not appear in the Raman spectrum of living cells.

\section{Conclusions}

FTIR and Raman micro-spectroscopy have proved to be very useful for the characterisation of both biomaterials and living cells used in tissue engineering.

The characterisation of biomaterials can be done with both techniques, FTIR and Raman spectroscopy providing complementary results. FTIR can rapidly be used to identify HCA formation on smooth samples using a reflection technique, or to characterise the bioactivity of powders using $\mathrm{KBr}$ diffuse reflectance method. For microscopic studies, such as bioactive fibres, the low signal-to-noise ratio of the FTIR microscope indicates that Raman micro-spectroscopy is a more powerful technique. Raman microspectroscopy is a non-destructive technique and can also be used for in situ measurements due to the low Raman signal of water. 
Table 1

Peak assignments for the MLE-12 Raman spectrum [31,45-49] (Phe - phenylalanine, Tyr - tyrosine, A - adenine, C - cytosine, $\mathrm{G}$ - guanine, $\mathrm{T}$ - thymine)

\begin{tabular}{|c|c|c|c|}
\hline \multirow{2}{*}{$\begin{array}{l}\text { Peak position } \\
\left(\mathrm{cm}^{-1}\right)\end{array}$} & \multicolumn{2}{|c|}{ Assignment } & \multirow[t]{2}{*}{ Reference } \\
\hline & DNA & Proteins & \\
\hline 1659 & & Amide I & [6] \\
\hline 1607 & & Phe, Tyr & {$[5]$} \\
\hline 1578 & $\mathrm{G}, \mathrm{A}$ & & {$[14]$} \\
\hline 1487 & $\mathrm{G}, \mathrm{A}$ & & [14] \\
\hline 1460 & & $\mathrm{CH}$ def & {$[5]$} \\
\hline 1449 & & $\mathrm{CH}$ def & {$[5]$} \\
\hline 1422 & $\mathrm{~A}, \mathrm{G}$ & & {$[14]$} \\
\hline 1375 & $\mathrm{~T}, \mathrm{~A}, \mathrm{G}$ & & {$[26]$} \\
\hline 1339 & A & $\mathrm{CH}$ def & {$[14,26]$} \\
\hline 1305 & A & $\mathrm{CH}$ def & {$[6]$} \\
\hline 1252 & A & Amide III & [14] \\
\hline 1240 & $\mathrm{~T}$ & Amide III & {$[14]$} \\
\hline 1209 & & Phe, Tyr & [14] \\
\hline 1176 & & Tyr, Phe & [14] \\
\hline 1155 & Ribode-phosphate & & [14] \\
\hline 1126 & & $\mathrm{C}-\mathrm{N}, \mathrm{C}-\mathrm{C}$ str & {$[5]$} \\
\hline 1095 & Blackbone $\mathrm{PO}_{2}^{-}$sym str & & {$[14]$} \\
\hline 1032 & & Phe & [14] \\
\hline 1004 & & Phe & [6] \\
\hline 937 & & Skel. C-C str & {$[6]$} \\
\hline 900 & Backbone & & {$[14]$} \\
\hline 853 & & Tyr & [14] \\
\hline 833 & Ribose-phosphate & & [14] \\
\hline 830 & & Tyr & [14] \\
\hline 789 & $\mathrm{C}, \mathrm{T}$, backbone OPO system & & {$[14,26]$} \\
\hline 751 & $\mathrm{~T}$ (ring breathing) & & {$[14,26]$} \\
\hline 729 & A (ring breathing) & & {$[14,26]$} \\
\hline 684 & G (ring breathing) & & {$[14,26]$} \\
\hline 669 & $\mathrm{~T}, \mathrm{G}$ & & {$[14,26]$} \\
\hline 645 & & Tyr (skeletal) & {$[5,14]$} \\
\hline 623 & & Phe (skeletal) & {$[5,14]$} \\
\hline
\end{tabular}

For the in situ study of individual living cells in the physiologic conditions, only the Raman microspectrometer is feasible, FTIR suffering from the strong absorption of water in infrared region. By use of high power $785 \mathrm{~nm}$ lasers, living cells can be sampled over long periods of time (as long as 40 minutes), in order to monitor continuously the biological state of the cells without altering the cell spectrum and morphology or inducing cell death. This is a considerable improvement over visible lasers, where cell damage occurs at much lower laser powers (few milliwatts) and irradiation times in the order of minutes.

Raman micro-spectroscopy allows spectra to be measured for cells cultured on different substrates, both bioinert (silica) and bioactive (45S5 Bioglass ${ }^{\circledR}$ and 58S glass). The substrates have no significant effects on the Raman spectra of the cells, except that interferences from the peaks belonging to HCA and calcite can occur. However, substantial spectral changes occur when dead cells are measured. These spectral changes establish the feasibility of using Raman micro-spectroscopy to obtain in situ analyses 


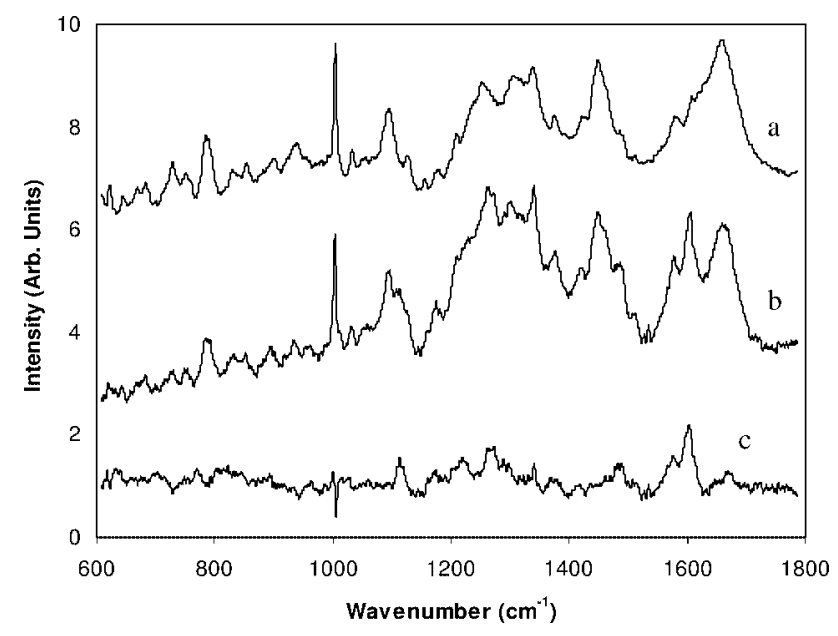

Fig. 10. Raman spectra of individual living (a) and dead (b) MLE-12 cells. (c) Calculated difference spectrum b - a.

of the biological state of the cells used in tissue cultures. Future improvements of this technique in conjunction with optical fibre probes and bioreactors will permit development of biodetectors based on living cells. These biodetectors should make it possible to identify various toxic agents and the study of the response and behaviour of the living cells to these agents. These studies can be complemented by biological studies such as gene expression analysis in order to identify the genes that are up or down regulated.

\section{Acknowledgements}

Acknowledgments go to the US Defence Advanced Research Projects Agency (Contract No. N66001C-8041) for financial support and to Renishaw plc. for technical assistance.

\section{References}

[1] L.L. Hench and J.K. West, Life Chem. Rep. 13 (1996), 187-241.

[2] L.L. Hench, Biomaterials 19 (1998), 1419-1423.

[3] J.R. Jones and L.L. Hench, Mater. Sci. Technol. 17 (2001), 891-900.

[4] W. Cao and L.L. Hench, Ceram. Int. 22 (1996), 493-507.

[5] L.L. Hencha and J. Wilson, Introduction to Bioceramics, Singapore World Scientific, Singapore, 1993.

[6] P. Revell, Pathology of Bone, Springer-Verlag, Berlin, 1986.

[7] L.L. Hench, R.J. Splinter, W.C. Allen and T.K. Greenlee, Jr., J. Biomed. Maters. Res. 2 (1971), 117-141.

[8] L.L. Hench, in: Bioceramics: Materials Characterisation Versus In Vivo Behavior, P. Ducheyne and J. Lemons, eds, Annals of New York Acad. Sci., New York 523, 1988, pp. 54.

[9] A.E. Clark, C.G. Pantano and L.L. Hench, Corrosion of Glass, 1-7, Magazines for Industry, New York, 1979.

[10] D.C. Greenspan, J.P. Zhong and G.P. LaTorre, Proc. 7th Conf. on Bioceramics, O.H. Andersson and A. Yli-Urpo, eds, Butterworth-Heinemann, Oxford, 1994, pp. 28-33.

[11] R. Li, A.E. Clark and L.L. Hench, J. Appl. Biomater. 2 (1991), 231-239.

[12] M.M. Pereira, A.E. Clark and L.L. Hench, J. Am. Ceram. Soc. 78 (1995), 2463-2468.

[13] M.M. Pereira, A.E. Clark and L.L. Hench, J. Biomed. Mater. Res. 28 (1994), 693-698.

[14] K.E. Wallace, R.G. Hill, J.T. Pembroke, C.J. Brown and P.V. Hatton, J. Mater. Sci.: Mater. Med. 10 (1999), 697-701.

[15] J. Wilson and D. Noletti, Proc. 3rd Conf. on Bioceramics, S. Hubbert, ed., Terre Haute, USA, 1990, pp. $283-302$.

[16] L.L. Hench and J.K. West, Chem. Rev. 90 (1990), 33-72. 
[17] L.D. Warren, A.E. Clark and L.L. Hench, J. Biomed. Mater. Res.: Appl. Biomater. 23 (1989), 201-209.

[18] R.G. Hill, J. Mater. Sci. Lett. 15 (1996), 112.

[19] L.L. Hench, D.L. Wheeler and D.C. Greenspan, J. Sol-Gel Sci. Technol. 13 (1998) 245-250.

[20] P. Sepulveda, J.R. Jones and L.L. Hench, J. Biomed. Mater. Res. 59(2) (2002), 340-348.

[21] P. Sepulveda, J.R. Jones and L.L. Hench, Proc. 13th Conf. on Bioceramics, S. Giannini and A. Moroni, eds, Trans Tech., Zurich, 2000, pp. 629-634.

[22] I.D. Xynos, M.V. Hukkanen, J.J. Batten, L.D. Buttery, L.L. Hench and J.M. Polak, Calcif. Tissue Int. 67 (2000), $321-329$.

[23] I.D. Xynos, A.J. Edgar, L.D. Buttery, L.L. Hench and J.M. Polak, Biochem. Byophys. Res. Comm. 276 (2000), 461-465.

[24] N. Jamin, P. Dumas, J. Moncuit, W.-H. Fridman, J.-L. Teillaud, G.L. Carr and G.P. Williams, Proc. Natl. Acad. Sci. USA 95 (1998), 4837-4840.

[25] S. Boydston-White, T. Gopen, S. Houser, J. Bargonetti and M. Diem, Biospectroscopy 5 (1999), 219-227.

[26] H.Y.N. Holman, M.C. Martin, E.A. Blakely, K. Bjornstad and W.R. Mckinney, Biopolymers (Biospectroscopy) 57 (2000), 329-335.

[27] H.Y.N. Holman, R. Goth-Goldstein, M.C. Martin, M.L. Russel and W.R. Mckinney, Environ. Sci. Technol. 34 (2000), 2513-2517.

[28] P. Lash, M. Boese, A. Pacifico and M. Diem, Vibrational Spectroscopy 848 (2002), 1-11.

[29] G.J. Puppels, F.F. de Mul, C. Otto, J. Greve, M. Robert-Nicoud, D.J. Arndt-Jovin and T.M. Jovin, Nature 347 (1990), $301-303$.

[30] J. Greve and G.J. Puppels, Raman microspectroscopy of single whole cells, in: Advances in Spectroscopy, Vol. 20, R.J.H. Clark and R.E. Hester, eds, John Wiley \& Sons, Chichester, 1993, pp. 231-169.

[31] I. Notingher, S. Verrier, H. Romanska, A.E. Bishop, J.M. Polak and L.L. Hench, Spectroscopy 16 (2002), 43-51.

[32] L.L. Hench, J. Am. Ceram. Soc. 74 (1991), 1487-1510.

[33] M.M. Pereira, A.E. Clark and L.L. Hench, J. Mater. Synth. Process. 2 (1994), 189-196.

[34] M.M. Pereira and L.L. Hench, J. Sol-Gel Technol. 7 (1996), 59-68.

[35] M. Blazewicz and C. Paluszkiewicz, J. Mol. Stuct. 563-564 (2001), 147-152.

[36] C. Ohtsuki, H. Kushitani, T. Kokubo, S. Kotani and T. Yamamuro, Apatite formation on the surface of ceravital-type glass-ceramic in the body, J. Biomed. Mater. Res. 25(11) (1991), 1363-1370.

[37] S. Huang and D.E. Ingber, The structural and mechanical complexity of cell-growth control, Nat. Cell Biol. 1(5) (1999), E131-E138.

[38] I. Rehman, R. Smith, L.L. Hench and W. Bonfield, Bioceramics 7 (1994), 79-84.

[39] I. Rehman, L.L. Hench and W. Bonfield, Bioceramics 6 (1993), 123-128.

[40] T. Peltola, M. Jokinen, S. Veittola, J. Simola and A. Yli-Urpo, J. Biomed. Mater. Res. 54 (2001), 579-590.

[41] M.S. Feld and J.R. Kramer, Am. Heart J. 122 (1991), 1803-1805.

[42] R.E. Rasmussen, M. Hammer-Wilson and M.W. Berns, Photochem. Photobiol. 49 (1989), $413-418$.

[43] G.J. Puppels, J.H.F. Olminkhof, G.M.J. Segers-Nolten, C. Otto, F.F. de Mul and J. Greve, Exp. Cell Res. 195 (1991), 361-367.

[44] R. Wolthuis, T.C. Bakker Schut, P.J. Caspers, H.P.J. Bushman, T.J. Romer, H.A. Bruining and G.J. Puppels, Raman spectroscopic methods for in vitro and in vivo tissue chararacterisation, in: Fluorescent and Luminescent Probes for Biological Activity, W.T. Mason, ed., Academic Press, London, 1999, pp. 433-455.

[45] E.A. Carter and H.G.M. Edwards, Biological applications of Raman spectroscopy, in: Infrared and Raman Spectrpscopy of Biological Materials, H.U. Gremlich and B. Yan, eds, Marcel Dekker Inc., New York, 2001, pp. 421-476.

[46] G.J. Puppels, H.S.P. Garritsen, G.M.J. Segers-Nolten, F.F. de Mul and J. Greve, Biophys. J. 60 (1991), 1046-1056.

[47] A. Mahadevan-Jansen and R. Richards-Kortum, J. Biomed. Optics 1 (1996), 31-70.

[48] D. Naumann, FT-infrared and FT-Raman spectroscopy in biomedical research, in: Infrared and Raman Spectroscopy of Biological Materials, H.U. Gremlich and B. Yan, eds, Marcel Dekker Inc., New York, 2001, pp. 323-377.

[49] S.A. Overman, K.L. Aubrey, K.E. Reilly, O. Osman, S.J. Hayes, P. Serwer and G.J. Thomas, Jr., Biospectroscopy 4 (1998), S47-S56.

[50] K.C. Blakeslee and R.A. Condrate, J. Am. Ceram. Soc. 54 (1971), 559-563.

[51] K. Nakamoto, Infrared and Raman Spectra of Inorganic and Coordination Compound, 5th edn, John Wiley \& Sons, New York, 1997 


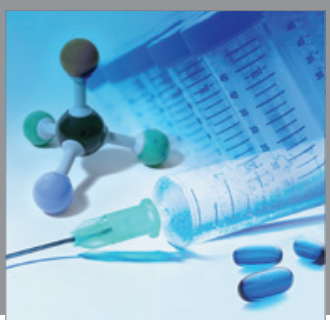

International Journal of

Medicinal Chemistry

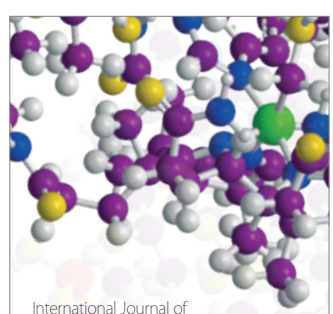

Carbohydrate Chemistry

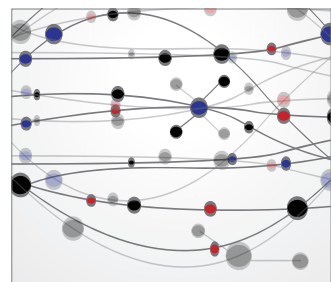

The Scientific World Journal
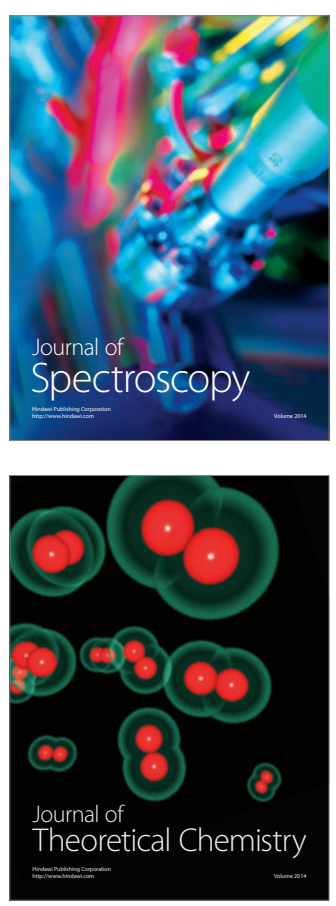
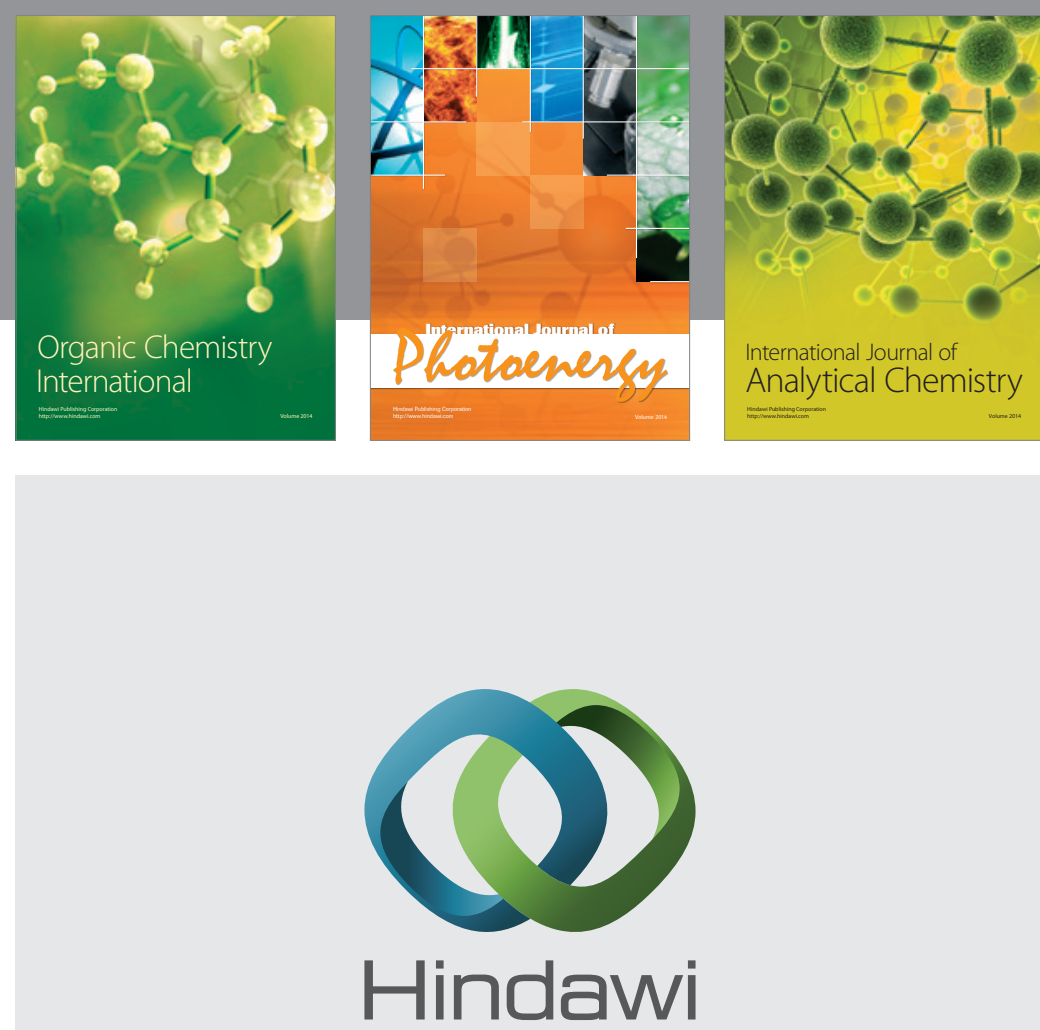

Submit your manuscripts at

http://www.hindawi.com
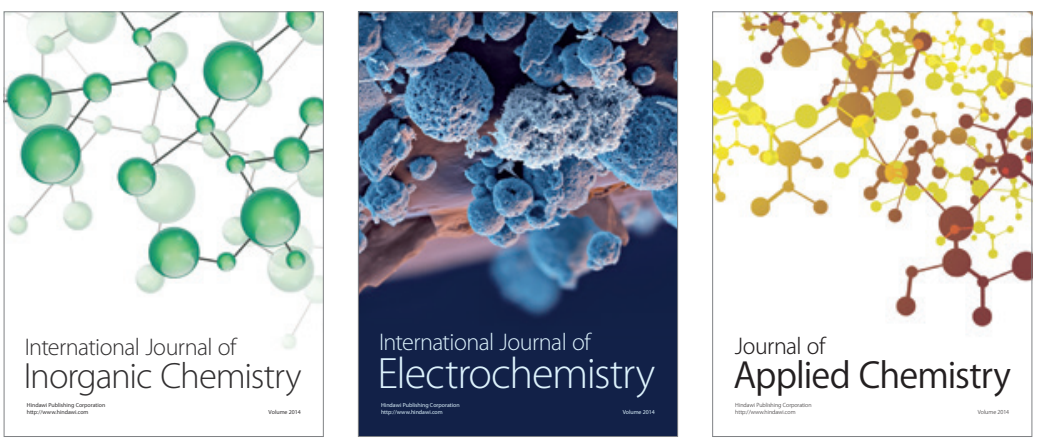

Journal of

Applied Chemistry
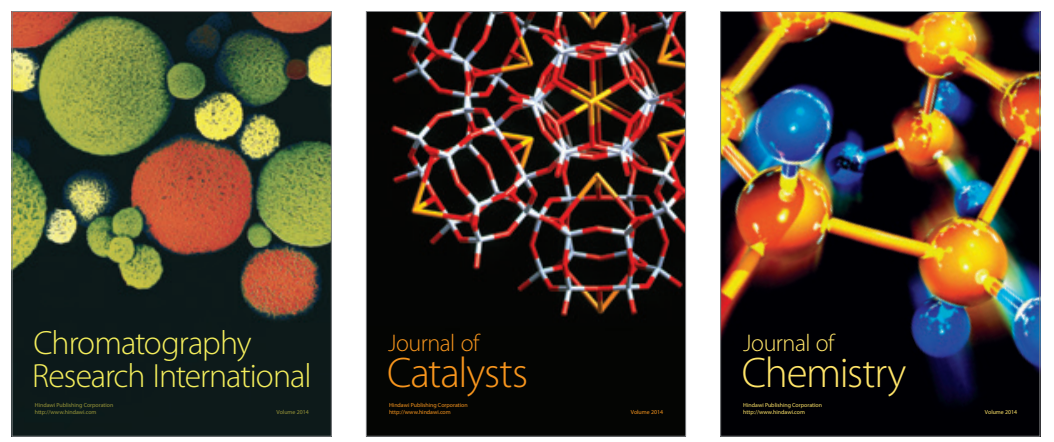
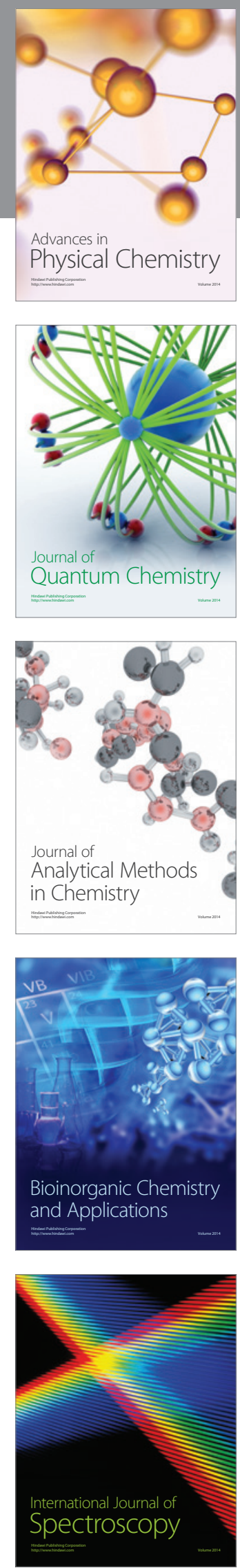